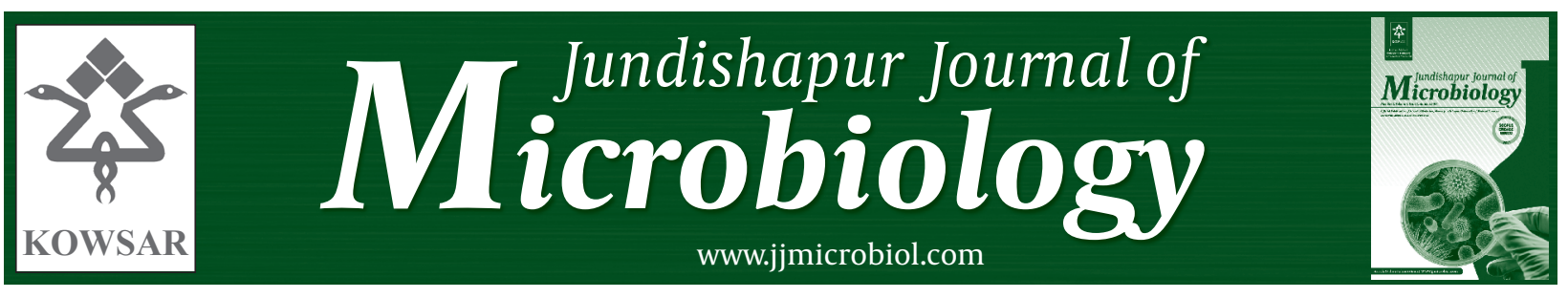

\title{
Serological Screening Test as a Tool for Early Prevention of Cancerous Disorders
}

\author{
Viroj Wiwanitkit ${ }^{*}$ \\ ${ }^{1}$ Wiwanitkit House, Bangkhae, Bangkok, Thailand
}

\begin{tabular}{l}
\hline A R T I C L E I N F O \\
\hline Article type: \\
Letter to Editor \\
\hline Article history: \\
Received: 7 Dec 2011 \\
Revised: 23 Feb 2012 \\
Accepted: 26 Feb 2012 \\
\hline Keywords: \\
Microbiology \\
Serology \\
Early Detection of Cancer
\end{tabular}

In medicine, there are many new evidence that some infections are the underlying risks contributing to the pre-cancerous lesion. The best examples are hepatitis infection that can lead to hepatoma and Helicobacter pylori infection which cause gastric carcinoma. The infectious induced cancers are important groups of cancers that are presently focused as preventable cancers. Since the infection is the early phase before development of pre-cancerous lesion, hence determination and treatment of infection means very early cutoff of the carcinogenesis process. The concept of cancer early diagnosis at present tends to the serological screening for the precancerous problem that is useful as a preventive mean for cancer control. The microbiological serological test becomes an important tool for this purpose. Several serodiagnostic tests are available as tools for early diagnosis of pre-cancerous lesions. In this specific brief article, the author summarizes and presents on some important serological screening that can be used as tools for early diagnosis and prevention of cancers. The main aim of this paper is to introduce the usage of screening test focusing on its effectiveness, pitfall and critical concerns, not on the already well-known pathology of

\author{
Please cite this paper as: \\ Wiwanitkit V. Serological Screening Test as a Tool for Early \\ Prevention of Cancerous Disorders. Jundishapur J Microbiol. \\ 2012;5(4):601-2. DOI: 10.5812/jjm.3722
}

Published by Kowsar Corp, 2012. cc 3.0.

infection induced carcinogenesis process.

\section{H. Pylori Serological Screening as Tool For Early Prevention of Gastric Cancer}

H. pylori infection is well documented as an underlying risk for gastric cancinogesis. H. pylori serological screening becomes a widely used tool for early prevention of gastric cancer at present. The prevention of $\mathrm{H}$. pylori-related diseases especially gastric cancer can be based on early treatment after screening procedure (1). Basically, the available ELISA serological tool for screening poses sensitivity and specificity about 82 - $96 \%$ and $67-92 \%$, respectively (2). Based on the available test, the error in serological determination has kept in mind. To select the test kit, it is necessary to evaluate the diagnostic property before implementation of the test. Therefore, the big concern about using the H. pylori serological screening is the accuracy of the test kits. The problem of false positive is common among the Asian cases with aged more than 45 years. Special awareness should be applied to the use of

\footnotetext{
*Corresponding author: Viroj Wiwanitkit, Wiwanitkit House, Bangkhae, P.O. Box:10160, Bangkok, Thailand.Tel:+66-24132436, Fax:+66-24132436, E-mail: wviroj@ yahoo.com

DOI: $10.5812 / j \mathrm{jm} .3722$

(C) 2012 Ahvaz Jundishapur University of Medical Sciences; Published by Kowsar Corp.

This is an Open Access article distributed under the terms of the Creative Commons Attribution License (http://creativecommons.org/licenses/by/3.0), which permits unrestricted use, distribution, and reproduction in any medium, provided the original work is properly cited.
} 
new general, point of care serological test for H. pylori serological screening. In addition to the basic problem due to the diagnostic property of the test kit, the economical concern on the use of $H$. pylori serological screening as tool for early prevention of gastric cancer should be discussed. Based on a recent report by Wiwanitkit et al., the high cost of the test kits becomes an important obstacle for implementation of the test as general tool for early prevention of gastric cancer (3). Nevertheless, the serological approach is still more cost effective than other alternative such as the urea breath test (4). To help implement the serological screening test, the policy marker has to adjust the test cost at reasonable price.

\section{Hepatitis B and Hepatitis C Serological Tool for Early Prevention of Hepatoma}

Hepatitis B and hepatitis C infections are the two wellknown viral infections that contribute to the liver cancer. The screening test for hepatitis B is widely used as a tool for early prevention of hepatoma, without doubt of its usefulness (5). Lin et al. recommended for "routinely screen Asian adults for HBV, regardless of their vaccination status (6)" as a strategy for liver cancer prevention. At present, the cost effectiveness analysis shows that the hepatitis B serological screening is acceptable for early liver cancer prevention (7). However, some facts on the use of hepatitis B serological test should be mentioned. After receipt of fresh frozen plasma transfusion, the incidences of the high rate of false positivity for anti-HBs and anti-HBc and false negativity for HBsAg are reported (8). In addition, the co-infection with hepatitis D virus can also suppress the gene product of hepatitis B virus resulting in transient negativity of HBsAg. Nevertheless, the remained question is whether application of only simple serological test is sufficient to fight with the high prevalence of disease in the endemic area.

Based on a recent report from a highly endemic country in Asia, it is suggested that serological test is not only sufficient since occult infection with seronegativity is not uncommon (9). Focusing on hepatitis $C$ serological screening test shows that it is less routinely used. Although it is recommended due to its usefulness, it is limitedly implemented. The main problem is due to the high cost of the screening test comparing to the basic test for hepatitis B. The screening is presently acceptable for focused patient groups with liver problem (10) or used as a blood safety screening in blood banking (11), not the population based mass screening; hence, it might not be a successful job for early prevention of hepatoma among the general population.

\section{EBV Serological Tool For Early Prevention of Nasopharyngeal Carcinoma}

Epstein-Barr virus (EBV) virus infection is confirmed as a lymph trophic viral infection and can be the cause of many lymphoid related cancers. The nasopharyngeal cancer, which is a common cancer in Southeast Asia, is reported to be related to EBV infection. The EBV serological tool is presently used for early prevention of nasopharyngeal carcinoma. The screening for the IgA antibody to EBV capsid antigen (VCA) is a very sensitive diagnostic test at present (12). It is presently recommended for the high risk populations such as those with problems of immune system (12). Nevertheless, there are also some important problems of using serological test. Fluctuations of serological antibodies can be observed and can lead to false results (13). Improved accuracy by combining application of circulating viral DNA and antibody is recommended (14). Focusing on the cost effectiveness issue, it is accepted that the screening can be useful only for the high risk population in non-endemic country (15).

\section{References}

1. Malfertheiner P, Selgrad M. Helicobacter pylori infection and current clinical areas of contention. Curr Opin Gastroenterol. 2010;26 (6):618-23.

2. Zalabska E. [Does the authentication of the antibodies against Helicobacter pylori have contribution to its diagnosis?]. Klin Mikrobiol Infekc Lek. 2011;17 (1):33-7.

3. Wiwanitkit V. Helicobacter pylori screening to prevent gastric cancer: an economical analysis for a tropical developing country. Asian Pac J Cancer Prev. 2010;11 (2):571-2.

4. Xie F, Luo N, Lee HP. Cost effectiveness analysis of populationbased serology screening and (13)C-Urea breath test for Helicobacter pylori to prevent gastric cancer: a markov model. World J Gastroenterol. 2008;14 (19):3021-7.

5. Yoon SK. Recent advances in tumor markers of human hepatocellular carcinoma. Intervirology. 2008;51 Suppl 1:34-41.

6. Lin SY, Chang ET, So SK. Why we should routinely screen Asian American adults for hepatitis B: a cross-sectional study of Asians in California. Hepatology. 2007;46 (4):1034-40.

7. Wiwanitkit V. Cost concern on hepatitis B virus screening for workers pursuing work aboard. Travel Med Infect Dis. 2009;7 (5):327.

8. Lim YA, Hyun BH, Kim DY. Effect of transfusion of fresh-frozen plasma on recipients' antibodies to hepatitis B surface antigen and hepatitis B surface antigen status in countries where hepatitis B virus is endemic. Vox Sang. 2002;83 (3):209-13.

9. Louisirirotchanakul S, Oota S, Khuponsarb K, Chalermchan W, Phikulsod S, Chongkolwatana V, et al. Occult hepatitis B virus infection in Thai blood donors. Transfusion. 2011;51 (7):1532-40.

10. Prevention of hepatocellular carcinoma in the Asia-Pacific region: consensus statements. J Gastroenterol Hepatol. 2010;25(4):657-63.

11. Wiwanitkit V. Anti HCV seroprevalence among the voluntary blood donors in Thailand. Hematology. 2005;10 (5):431-3.

12. Wiwanitkit V. Summary On The Prevalence Of Serum VCA-IgA Antibody Among Thai Patients With Lymphoma: An Implication For Risk And Screening Purpose. Int J Trop Med. 2005;2 (2).

13. Cao SM, Liu Z, Jia WH, Huang QH, Liu Q, Guo X, et al. Fluctuations of epstein-barr virus serological antibodies and risk for nasopharyngeal carcinoma: a prospective screening study with a 20-year follow-up. PLoS One. 2011;6 (4):e19100.

14. Leung SF, Tam JS, Chan AT, Zee B, Chan LY, Huang DP, et al. Improved accuracy of detection of nasopharyngeal carcinoma by combined application of circulating Epstein-Barr virus DNA and anti-Epstein-Barr viral capsid antigen IgA antibody. Clin Chem. 2004;50 (2):339-45

15. O TM, Yu G, Hu K, Li JC. Plasma Epstein-Barr virus immunoglobulin A and DNA for nasopharyngeal carcinoma screening in the United States. Otolaryngol Head Neck Surg. 2007;136 (6):992-7. 